\title{
MOCONDINO EN SU HISTORIA: LA ABOLICIÓN DE SU RESGUARDO
}

\author{
Por: Dumer Mamián Guzmán ${ }^{1}$
}

\section{RESUMEN}

El presente artículo es resultante de la investigación acerca de "La disolución y reestructuración de los resguardos quillasingas del Valle de Atriz", financiada por la Vicerrectoría de Investigaciones, Posgrados y Relaciones Internacionales - VIPRI. La investigación aborda el interrogante sobre los procesos de disolución y parcelación de los resguardos indígenas de origen colonial que existían en los alrededores de la ciudad de San Juan de Pasto hasta 1950, y cuál su relación con los actuales procesos de reestructuración. A partir de una contextualización básica del problema y con el aporte de expedientes del Archivo General de la Nación y el Archivo Histórico de Pasto, se explorara los avatares históricos de estos procesos en el resguardo quillasinga de Mocondino.

Palabras claves: Resguardo, gobierno, parcialidad, disolución.

JEL: $20 Z$

1. Profesor tiempo completo del Departamento de Humanidades y Filosofía y Coordinador Instituto Andino de Artes Populares -IADAP, de la Universidad de Nariño. Email: dumermg@hotmail.com Artículo recibido: 8 de abril de 2015 


\title{
THE HISTORY OF TERRITORIAL UNIT IN MOCONDINO THE ABOLITION OF THE IN MOCONDINO
}

\author{
By: Dumer Mamián Guzmán²
}

\begin{abstract}
This article is resulting of a the research about "The dissolution and restructuring of guards quillasingas of the Valle de Atriz", promoted by the ViceRector for Research , Graduate Studies and International Relations - VIPRI. The research addresses the question on the processes of dissolution and fragmentation of the indigenous reservations of colonial origin that existed in the vicinity of the city of San Juan de Pasto until 1950, and what its relationship with the current restructuring processes. From a basic problem and contextualization with input from records of the General Archives of the Nation and Historic Archives of San Juan de Pasto, we will search historic avatars of these processes in the Quillasinga Guard in Mocondino.
\end{abstract}

Key words: Guard, Government, Parciality, Disolution

JEL: $20 Z$

2. Fulltime teacher in Departamento de Humanidades y Filosofía de la Universidad de Nariño, Coordinador, Instituto Andino de Artes Populares - IADAP. 


\title{
MOCONDINO EM SUA HISTÓRIA: A SUPRESSÃO DO RESGURDO DE MOCONDINO
}

\author{
Por: Phd Dumer Mamián Guzmán
}

\section{RESUMO}

Este artigo é o resultado de pesquisa sobre "La disolución y reestructuración de los resguardos quillasingas del Valle de Atriz", pesquisa financiada pela Investigação Vicerretory, Pos-graduação e relaçoes Internationais - VIPRI. A pesquisa aborda a questão dos procesos de dissolução e fragmentação dos resguardos indígenas existentes em torno da cidade de San Juan de Pasto até 1950, e qual seu relação com os procesos existentes de reestructuração. A partir de uma contextualização básica do problema e com a contribução de expedientes do Archivo General de la Nación e o Archivo Histórico de Pasto, são explorados os avatares históricos destes procesos no resgurdo quillasinga de Mocondino

Palavras Chaves: resguardo, cabido, parcialidade, dissolução

JEL: $20 Z$ 


\section{INTRODUCCIÓN}

La ciudad de San Juan de Pasto y sus entornos, conformados por una serie de pueblos de antigua tradición, sufren continuamente transformaciones abruptas que obedecen a intereses y políticas institucionales que paulatinamente los trastocan en su vida cultural. Ante esta situación los pobladores reaccionan con estrategias como la revitalización de órdenes culturales, territoriales y políticos ancestrales, especialmente reorganizando y revitalizando las parcialidades, cabildos y resguardos indígenas de origen colonial. Alternativa del mal gusto para el "progreso" institucional, por lo cual las autoridades e instituciones gubernamentales la ignora o la niega de manera intransigente, suscitando fuertes conflictos.

Se desconoce o niega tanto los procesos y estructuraciones territoriales y culturales que subyacen a los ordenamientos político-administrativos modernizantes, como los cambios que, en Colombia, a partir de la Constitución de 1991, se dieron en cuanto al concepto de Estado-nación y, por ende, en el ordenamiento jurídicopolítico.

La disolución de los resguardos y cabildos en 1950 obedeció a políticas estatales que estaban en correspondencia con modelos económicos y políticos que orientaban la dirección del Estado. A mentalidades que concebían la nación y la libertad en los términos decimonónicos del republicanismo liberal, donde no tienen cabida los pueblos indígenas, ni sus formas colectivas de vida, ni sus formas propias de gobierno. Políticas requeridas en Pasto por la integración acelerada de la región al "desarrollo nacional", dominado por el mercado.

Habiendo sido negados dentro del ordenamiento jurídico como indígenas de resguardo y cabildo, sin embargo, continuaron en relaciones subalternas, resistiendo con sus derechos y obligaciones colectivos, compartiendo y manteniendo su territorio, sentimientos de identificación con su pasado aborigen, así como formas de gobierno y control social internos distintos de otras formas culturales y sociales de vida. Modos de ser y de existir que son los que hoy afloran, tal vez ambiguamente, frente a los modelos y mentalidades implementadas por urbanizadores y ordenamientos territoriales municipales.

Estos pueblos aborígenes resistiendo lograron sobreaguar los distintos regímenes funestos a sus derechos, desde la Conquista, la Colonia y la República. Establecida la República de Colombia en 1886, de acuerdo a los parámetros ideológicos y políticos de la regeneración conservadora, en seguida, 1980, se dictó la Ley 89 de 1890 con la cual se dio un plazo de 50 años para terminar de reducir a los indígenas a la vida civilizada, y, en consecuencia, liquidar por obsoletos todos los Resguardos Indígenas del país para que estas tierras entraran a la economía como propiedad privada.

No obstante, antes de este término se dictó la Ley 19 de 1927 mediante la cual se autorizó, a través de comisiones repartidoras, parcelar los resguardos entre las familias comuneras. Sin embargo, la situación política del país y sobre todo la resistencia indígena, especialmente planteadas en los departamentos del Cauca con la "quintinada", alusiva a la lucha liderada por Manuel Quintín Lame Chantre, y en 
Nariño las "marchas de las legislaturas" lideradas por los cabildos, no permitieron su ejecución inmediata ${ }^{3}$.

Obcecados en su decisión los padres de la patria siguieron insistiendo, así que, diez años después, el presidente liberal Eduardo Santos Montejo (1938-1942), con su ministro de Economía Nacional, Jorge Gartner de la Cuesta, decidieron aplicar la Ley e iniciar, mediante el Decreto 2454 de 1939, la abolición y repartición de los resguardos, tomando como piloto el resguardo de San Lorenzo, en el Municipio de Ríosucio, departamento de Caldas. Se tomó como piloto este resguardo por los intereses económicos que allí tenía el ministro Gartner: explotar la mina de oro de Marmato.

Pero los términos de la Ley dificultaron la repartición, por lo cual, el gobierno, administrativamente y de manera arbitraria lo declaró baldío, desconociendo al resguardo como propiedad colectiva y a los comuneros como legítimos poseedores, siempre con el fin de facilitar la compraventa y apropiación privada de los interesados en la tierra y las minas.

Para tal efecto expidió el Decreto 1421 de 1940, firmado por el presidente Santos, por Jorge Gartner, ahora Ministro de Gobierno, y por Miguel López Pumarejo Ministro de la Economía Nacional, con el cual se estableció el título original colonial como único sustento de vigencia y legalidad de un resguardo. Se autorizó al Ministerio de la Economía Nacional como la instancia responsable para adelantar tal proceso.

Operando con estos procedimientos administrativos engañosos y dolosos el Ministerio de Economía Nacional, Departamento de Tierras, Sección de Baldíos, promovió múltiples procesos para declarar abolidos un sinnúmero de resguardos indígenas, estableciendo que estas tierras eran baldías, que, por consiguiente, no habían salido del patrimonio del Estado-nación. Y que los indígenas, los más antiguos pobladores y poseedores de ellas, quedaban como simples colonos cultivadores en suelo de la nación. Así, las tierras y comuneros de los resguardos quedaban a disposición para ser repartidos, rematados y enajenados por propietarios y hacendados particulares. Así lo rememora don Alonso Maigual:

Vivir hemos vivido todo nuestro tiempo pasado aquí en esta región, nacidos aquí. Somos netamente gualmatanes, mis padres, ellos, habían sido los pri-

3. Como respuesta a esta ofensiva entre 1910 y 1917 nació el movimiento dirigido por Quintín Lame, que comenzó con la consigna "no al terraje" para concretarse en lo que fue el programa de lucha de los indígenas en el presente siglo, cuyos aspectos básicos eran: 1- La defensa de las parcialidades indígenas y el rechazo a las leyes de extinción de los Resguardos. 2- La negativa a pagar terraje y el rechazo a la servidumbre. 3- La afirmación de los cabildos como centros de autoridad autónoma de los indígenas y como base de organización. 4- La recuperación de las tierras usurpadas por los terratenientes desconociendo todos los títulos que no se basaran en Cédulas Reales. 5- La afirmación de los valores culturales indígenas y el rechazo de la discriminación racial y cultural en contra de los indígenas colombianos. 6- La unificación de los Resguardos del Cauca y del país para constituir la "República Chiquita" al margen de los blancos, con un cacique general. 7- Representación especial de los indígenas en Consejos, Asambleas y Congreso "porque si los blancos ordenan que repartamos los Resguardos entonces habrá en el Congreso indígenas que ordenarán a los blancos también repartir lo suyo entre los terrajeros, pues Dios dio la tierra para que todos los hombres fueran dueños de un pedazo". 
meros fundadores del pueblo. Somos de la parcialidad de aquí, como hijuelos de los caciques, somos positivos de aquí. Antes éramos los de nosotros, solo los nuestros. Esto había sido grande porque esto había sido pueblo. Pero cuando ya se hicieron dueños los ricos, aparecieron los límites de las haciendas. En Catambuco, por ejemplo, apareció la hacienda de los Zaramas. Cuando se ofreció revisar la delimitación los mayores buscaron, gastaron. Las escrituras habían estado en Quito, pero desaparecieron. Las haciendas al principio habían sido del río para atrás (Mamián, 2000:77).

Con estos acomodos legales y administrativos se negó de un plumazo la posesión y propiedad territorial de los indígenas desde antes de la Conquista, y los reconocimientos legales de este derecho, tanto del régimen colonial, como del republicano. Reconocimientos establecidos desde las Ordenanzas de San Lorenzo en 1584, en tiempos de Felipe II, y por las leyes de Procedimiento Civil, desde 1825, en tiempos de la nueva República.

Además, la Ley 89 de 1890, en su Artículo 12, y el Decreto 74 de 1898, reglamentario, en su Artículo 39, eran claros en manifestar que a falta de títulos coloniales o por pérdida de ellos, el título de dominio de las parcialidades se podía demostrar por un título supletorio, mediante la declaración jurada, con cinco testigos, de la posesión treintenaria. Dice el Artículo 12:

En caso de haber perdido una parcialidad sus títulos por caso fortuito o por maquinaciones dolosas y especulativas de algunas personas, comprobará su derecho sobre el resguardo por el hecho de la posesión judicial o no disputada por el término de treinta años, en caso que no se cuente con esa solemnidad, y de acuerdo con lo dispuesto en el Código Civil. Este último requisito de la posesión pacífica se acredita por el testimonio jurado de cinco testigos de notorio abono, examinados con citación del Fiscal del Circuito, los que expresarán lo que les conste o hayan oído decir a sus predecesores, sobre la posesión y linderos del resguardo (Ley 89 del 25 de diciembre de 1890).

Así las cosas, en 1943, en la presidencia de Alfonso López Pumarejo, aplicando el Artículo 14 del Decreto-Ley 1421, y desconociendo el título legítimamente reconstituido en 1836 ante el juez de Supía, el Ministro de Economía Nacional, resolvió, por vía administrativa ${ }^{4}$, que el Resguardo de San Lorenzo no existía, que la comunidad de San Lorenzo "carece de la titulación necesaria para tener tal calidad y que, en consecuencia, sus terrenos no han salido del patrimonio del Estado”, “que los terrenos eran terrenos baldíos de propiedad de la nación, y que los indígenas éramos colonos que estábamos invadiendo tierras del Estado"5.

4. Desde 1820 y hasta 1927 la competencia para definir la propiedad de las comunidades indígenas sobre sus tierras de Resguardo estaba radicada en los jueces.

5. Dice la Resolución $N^{o} 1$ de 1943, del Ministerio de la Economía Nacional, en lo pertinente: El Ministerio de la Economía Nacional, en uso de la autorización expresamente concedida por el artículo 14 del Decreto-ley 1421 de 1940, "RESUELVE: "Primero. Declarar que el llamado Resguardo de San Lorenzo, situado en el Municipio de Riosucio, Departamento de Caldas, y cuyos linderos se transcriben a continuación, carece de la titulación necesaria para tener tal calidad y que, en consecuencia, sus terrenos no han salido del patrimonio del Estado". 
Con este antecedente piloto, en seguida, se declararon inexistentes otros resguardos de Colombia y por supuesto de los Departamentos de Cauca y Nariño. En Nariño, por Resolución No. 7 de 30 de mayo de 1947, se declararon extinguidos los resguardos de Santa Bárbara y Santa Bárbara de Anganoy. Inmediatamente entraron en turno para su estudio las solicitudes hechas por los parcialistas de Aranda, La Laguna, Anganoy y Santa Rosa de Cunchuy ${ }^{6}$.

El resguardo de Obonuco fue extinguido en 1947, y las 70 hectáreas de terreno se dividieron entre 200 familias; muchas de las cuales no recibieron sus lotes por ser imposible acomodarlas. El de Anganoy lo fue en 1948, por insistencia del propio gobernador indígena; y "dado que la extensión era pequeña, por la invasión de las haciendas vecinas, el resguardo estaba reducido prácticamente al pueblo semiurbano, quedando para cada familia microfundios de 500 metros cuadrados. El de Mocondino en 1948. El de Jongovito en 1949, por insistencia del propio gobernador Alejandro Tulcán; sus 84 hectáreas fueron repartidas entre más de 100 familias, resultando extensiones menores de un cuarto de hectárea por familia. El de Gualmatán en 1951, también con la autorización del cabildo presidido por Faustino Maigual. ${ }^{7}$ Todos extinguidos con el mismo argumento con el cual fue abolido el de San Lorenzo, es decir, carecer de la titulación necesaria al no encontrarse el título colonial en los archivos notariales u otros de Pasto, Popayán y Quito, y que, en consecuencia, eran terrenos baldíos de propiedad de la nación que no habían salido del patrimonio del Estado.

En todos los casos, debido a la rebatiña por quedarse con la poca tierra dejada por los hacendados, se generaron conflictos y crímenes entre los mismo indígenas (Fals Borda, 1959:11).

\section{LOS AVATARES DEL RESGUARDO DE MOCONDINO}

Mediante Resolución No. 12, de enero 20 de 1948, el Ministerio de Economía Nacional, Departamento de Tierras, Sección de Baldíos, resolvió: Primero: Declarar que el Resguardo de Mocondino carecía de la titulación necesaria para tener la calidad de Resguardo de indígenas de acuerdo con la Ley 89 de 1890 y el Decreto 74 de 1898 y que, por derivación, estos terrenos no habían salido del patrimonio del Estado ${ }^{8}$. Segundo: Que los indígenas que componían la parcialidad de Mocon-

6. Firma Luis Roberto García. Jefe de la Sección de Baldíos. Agosto 11 de 1947. Archivo General de la Nación, Sección República, Fondo Ministerio del Interior, Asuntos Indígenas, Caja 184, Carpeta 1542, año 1939-1957, folios 6-7.

7. Claudia López, señala que, de acuerdo a la Oficina de Asuntos Indígenas de Nariño, entre 1944 y 1958 se desestructuraron los resguardos de Pandiaco, Buesaquillo, Genoy, Chachaguí, La Laguna, Obonuco, Pejendino, Puerres, Tescual, Chanchala, Anganoy, Gualmatán, Mocondino, Jongovito, Catambuco, Jamondino, Betanilla (LÓPEZ, C. Pueblos del Valle de Atrís, actuales habitantes del antiguo territorio Quillasinga. Geografía Humana de Colombia. Tomo IV, Volumen I, Instituto Colombiano de Cultura Hispánica, Bogotá, 1996).

8. Los resguardos, aunque hubo intentos de abolirlos, en ningún momento fueron considerados patrimonio del Estado. 
dino $^{\mathbf{9}}$, según los respectivos censos, solo tenían derecho a que se les adjudicara la parte que tuvieran cultivada y ocupada con ganados, añadiéndole otro tanto del terreno adyacente inculto -si acaso lo hubiere- en la forma establecida por las leyes vigentes sobre baldíos. Tercero: que de acuerdo con el Artículo $3^{\circ}$ de la Ley 60 de 1916, no podrán adjudicarse esos terrenos del resguardo a personas extrañas a la misma parcialidad. Los linderos quedaron establecidos así:

... por el Oriente, con terrenos del Resguardo de la Parcialidad de la Laguna, una cordillera y el filo del Tábano por medio; por el Sur, con Las propiedades llamadas Santa Lucía, Bosques y con propiedades llamadas del Señor Juan Gregorio Espinosa, una Cordillera y la quebrada denominada "Palmas" al medio así como también hay por medio dos mojones en tierra en el punto donde colinda con propiedades del Espinosa. El primer mojón queda junto a un árbol de manduro señalado con el número 1; y el segundo se halla colocado diez metros más debajo de otro mojón colocado a la orilla de la quebrada Riobobo. Esta quebrada aguas abajo hasta la confluencia con la quebrada Casanare formando en esta parte una punta de reja; por el occidente, con la hacienda denominada "El Campanero" de propiedad del Señor Enríquez Salas Pérez y otros más y también con la hacienda del Señor Manuel José Luna, quebrada Casanare por medio, luego y frente a un potrero atraviesa el lindero desde la quebrada Casanare para arriba siguiendo en un todo y lindero de la hacienda del expresado Señor Luna hasta llegar a la cimas desde donde se divisa la Ciudad de Pasto, de aquí linda con el Resguardo de la Parcialidad de Jamondino, cuchilla al medio, esta cuchilla hacia abajo hasta llegar a un árbol de manduro marcado con dos cruces, de allí para abajo a dar a otro manduro señalado con una cruz, por el Norte con el resguardo de Puerres y Canchala, zanja y bordo al medio; de aquí el camino de la Cuchilla que conduce al pueblo de Mocondino, sirviendo este camino de lindero entre las Parcialidades de Mocondino y Jamondino, hasta dar a un mojón divisorio de los Jamondinos con los herederos del Señor Braulio de la Rosa, de este mojón hacia abajo siguiendo, por el mismo camino deslindado ya el Resguardo de Mocondino con la hacienda de los Señores Rosas hasta llegar a una boca zanja, la que servía a poco trecho, de allí sigue una cuchilla zanjada en parte y en parte sin zanjar, la que va a descansar a propiedad de Ramón Jojoa deslindado en toda la extensión desierta con la finca denominada Chiriurco de Rómulo Chicaiza Nieto y José Rafael Agreda y Doctor Luis E. Gavilanes hasta topar con el Pueblo de Puerres y Canchala, zanja a bordo al medio; de allí linda con el potrero llamado "Bomba" de los huérfanos, camino y zanja al medio, de allí con la finca de Burbanos, Florentino Paz, Padre Juan Bautista Rosero, heredero de José Moisés Matinés y Fidencio Luna, Germán Martínez, Julián Jojoa y de otros muchos más propietarios hasta llegar a la quebradas Tambillo y sigue ésta aguas arriba hasta el punto denominado Tambillo, de aquí cruza lindero con la parcialidad de la Laguna hasta dar a la Cima Casanare y filo del Tábano, en toda esta esta extensión hay camino en parte por medio y en

9. Al ser reconocida como parcialidad con Cabildo, de hecho se reconoce que viven en la tierra común de resguardo. 
parte zanja...” Firman: Moisés Prieto por el Ministerio de Economía Nacional, Jorge López Posada como Secretario General del Ministerio ${ }^{\mathbf{1 0}}$.

Ahora bien, el argumento del Ministerio fue: "Los indígenas de Mocondino han solicitado en repetidas ocasiones que, de conformidad con la Ley 19 de $1927 \mathrm{y}$ del Decreto legislativo No. 1421, de 1940, proceda a declarar la extinción de dicho resguardo para poder solicitar cada parcialista la adjudicación definitiva de las parcelas que de tiempo atrás han venido ocupando y poseyendo sin interrupción alguna"11 Y porque "El Resguardo de Mocondino no tiene títulos originarios que acrediten su constitución o nacimiento a la vida jurídica, de acuerdo con las disposiciones de la Ley 89 de 1890." Puesto que, "como consta en el expediente y lo certifica el Notario titular No. 1, del Circuito de Pasto, 'Revisados los libros protocolarios de esta oficina no se encuentra el título originario de la Corona Española sobre transmisión del dominio de los terrenos del Resguardo de Mocondino, de este municipio a favor de la comunidad nombrada'. ${ }^{12}$

Enfatiza que, el resguardo y la parcialidad de Mocondino para que tengan el carácter de tales, es menester que dispongan de los títulos originarios emanados de la Corona Española que acrediten su existencia legal, o, en su defecto, la prueba de que trata el Artículo 12 de la Ley 89 de 1890. Y como no los tiene, "por carecer de los títulos originarios de la Corona Española, el resguardo de indígenas de Mocondino, se encuentra en las mismas condiciones de los Resguardos de Pandiaco, Catambuco, Pejendino, Santa Bárbara y Santa Bárbara de Anganoy es el caso, como se hará al final de la presente providencia, de decretar la extinción del Resguardo en cuestión"13.

Declarado el resguardo tierra baldía, las personas establecidas en ellos por siglos, con casa y cultivos, quedaron como cultivadores en suelo ajeno, el suelo baldío llamado suelo de la nación. Dice la Resolución: "no existiendo por tal causa la entidad jurídica resguardo por una parte, y estando por otra un número de personas establecida con casa de habitación y cultivos de varias clases en los terrenos materia de esta providencia, como confirma el censo de la parcialidad, la situación de estos es la de tierras baldías y la de aquellos, la de cultivadores en suelo de la Nación"14.

10. Resolución No. 12, emitida por el Ministerio de Economía Nacional, Departamento de Tierras, Sección de Baldíos. Archivo General de la Nación, Sección República, Fondo Ministerio del Interior, Asuntos Indígenas, Caja 265, Carpeta 2523, año 1948, folios 6-7. Linderos que, como veremos en la referencia 16, corresponden a la declaración jurada, en noviembre de 1927, de los señores Delfín, Julián, Leopoldo y Pablo Jojoa, Camilo Carlosama, Diógenes Eraso y Misael Masinsoy, y, en consecuencia, a la escritura 412 de 24 de noviembre de 1927.

11. Ibíd., folios 30-50.

12. Retoma el informe del Notario Alfredo Santander. Ibíd., folio. 25r.

13. Resolución No. 12. Ibíd., folio 3r.

14. Ibíd., f. 2.

Según informe del Cabildo, Mocondino estaba constituido por 256 habitantes, un cabildo formado por siete miembros, una escuela pública mixta, y sus miembros hablan el idioma castellano, tienen un grado de cultura regular y sus miembros se hallan dedicados, casi en su totalidad a la agricultura. Informe enviado por miembros del cabildo encabezados por el Alcalde Gonzalo Jojoa, al ministro de Economía Nacional Departamento de Tierras y Baldíos el 8 de agosto de 1947. Ibíd., folio16r. 
Sin embargo, por Escritura No. 412 de 1927 de 24 de Noviembre, Notaría Segunda de Pasto, se protocolizaron diligencias referentes a la creación del título de la parcialidad de Indígenas del Pueblo de Mocondino, que demuestra su existencia legal, de acuerdo con el Artículo 12 de la Ley 89 de 1890, con los Artículos 39, 40 y 41 del Decreto 74 de 1898 y con el Ordinal $4^{\circ}$ del Artículo 229 de la Ley $4^{\mathrm{a}}$ de 1913. De modo que, si bien, es verdad que por el saqueo de los archivos, los títulos originarios coloniales desaparecieron, no obstante, los mocondinos acreditaron el tan exigido título del Resguardo restablecido acorde con el Artículo 12 de la Ley 89.

En más de una oportunidad judicial y extrajudicial los Cabildos aclaraban que siguiendo el proceso indicado por el Artículo 12 de la Ley 89, probaron que sí tuvieron título originario, títulos que fueron saqueados para favorecer intereses ajenos; pero que con la memoria de los antiguos se pudieron reconstruir las linderaciones y levantar los planos.

El Título fue restablecido siguiendo el proceso legal correspondiente. Mediante memorial del 8 de Noviembre de 1927, el Honorable cabildo de indígenas de Mocondino (representado en el Alcalde Mayor Juan Bautista Jojoa, el Alcalde Segundo Clodomiro Pinto, el Regidor Mayor Modesto Jojoa, el Alguacil Luis Emigdio Naspirán y los Fiscales y Fiscalitos Eusebio Jojoa), expuso lo siguiente al Señor Fiscal del Honorable Tribunal Superior del Distrito Judicial de Pasto (representado en la persona del ser Carlos Benavides Guerrero):

I. El título que demuestra la propiedad y el dominio de nuestro resguardo de Mocondino, ha desaparecido, tal vez por la acción del tiempo, tal vez por no existir, sin que hasta la fecha tengamos dato alguno acerca de su existencia encontrándonos por lo tanto imposibilitados de poder comprobar la posesión de tierras comunales que en verdad nos pertenecen.

II. Desde tiempo inmemorial venimos usufructuando en nuestra calidad de indígenas del resguardo de Mocondino, toda la extensión de tierras que desde el tiempo del Rey se nos adjudicó, para poder así atender a todas nuestras necesidades.

III. Hoy que el número de familias ha crecido considerablemente y por tanto los habitantes de nuestro resguardo de Mocondino, a quienes representamos, han aumentado de un modo sorprendente, tratamos de precisar de un modo concreto y determinado los linderos de nuestro resguardo.

IV. La porción de terrenos comunales, descritos por los linderos que luego demostraremos con testimonios fidedignos, ha sido siempre respetada como tal por todas las Autoridades del lugar.

V. La ley 89 de 1890 en su Artículo 12, ha previsto el caso de pérdida o no existencia de un título de resguardo de una parcialidad. Este Artículo pues da la facultad de crear o de rehacer el título desaparecido, comprobando con el testimonio de cinco testigos de notorio abono, la posesión pacífica y no interrumpida por el lapso de treinta años, con la precisa determinación 
de sus linderos. Idéntico procedimiento dispone el Artículo 39 del Decreto 74 de $1898^{15}$.

Para comprobar la posesión pacífica que por más de treinta años gozaban en el resguardo de Mocondino y para establecer de un modo preciso los linderos, citaron como testigos a los señores Delfín Jojoa, Camilo Carlosama, Diógenes Eraso, Pablo Jojoa, Leopoldo Jojoa, Misael Mansisoy y Julián Jojoa, a quienes, entre el 14 y 17 de Noviembre de 1927se les efectuó el correspondiente interrogatorio. Especialmente referido a que "expresen si es verdad y les consta a ciencia cierta, que desde tiempo muy inmemorial, en el pueblo de Mocondino ha existido siempre una comunidad de indígenas, la que siempre ha poseído y usufructuado, sin interrupción alguna y con la protección de todas las autoridades del lugar una porción de terreno de resguardo o comunal, el que ha estado siempre y está bajo la vigilancia inmediata del Cabildo de Mocondino". Precisando "todos y cada uno de los linderos, por los cuales se halla circuido el resguardo de Mocondino". Que expresen, así mismo, "si la linderación que dejan descrita, la conocen por propia y directa percepción, ya por haber recorrido íntegramente y varias veces, ya por haber levantado planos, y ya por haber acompañado a las autoridades que la han recorrido, con el solo fin de tener conocimiento de ella”.

Para demostrar la honorabilidad, honradez e idoneidad de los testigos, y para el efecto de abonarlos como lo requería la Ley, entre el 17 y 18 de Noviembre, se recibió declaración jurada a los señores José Francisco Naspirán, José Mariano Pinza, Manuel Trinidad Naspirán, Juan E. Criollo y José Criollo; quienes expresaron conocer personalmente ya muchos años "de trato, vista y comunicación" a los señores Delfín, Julián, Leopoldo, Pablo Jojoa, Camilo Carlosama, Diógnes Eraso y Misael Masinsoy, y les consta que "son personas honradas, trabajadoras, de muy buena reputación y en un todo honorables".

Los testigos coincidieron en los siguientes linderos:

... por el Oriente, con terrenos del Resguardo de la Parcialidad de la Laguna, una cordillera y el filo del Tábano por medio; por el Sur, con las propiedades llamadas Santa Lucia, Bosques y con Propiedades llamadas Santa Lucia, Bosques y con propiedades del Señor Juan Gregorio Espinosa, una Cordillera y la quebrada denominada "Palmas" al medio así como también hay por medio dos mojones en tierra en el punto donde colinda con propiedades del Espinosa. El primer mojón queda junto a un árbol de manduro señalado con el número 1; y el segundo se halla colocado diez metros más debajo de otro mojón colocado a la orilla de la quebrada Riobobo. Esta quebrada aguas abajo hasta la confluencia con la quebrada Casanare formando en esta parte una

15. Diligencias dirigidas al señor Fiscal del Tribunal Superior, por el Cabildo de la parcialidad de Mocondino, para efecto de la creación de un título y de la recepción de una prueba. Archivo Histórico de Pasto, Fondo Notarías, Año de 1927, folio 196.

Se envía este memorial considerando las atribuciones de este Ministerio Público, que, además de ser el protector de indígenas, le corresponde lo establecido por el Ordinal $4^{\circ}$ del Artículo 229 de la Ley $4^{\text {a }}$ de 1913, en lo que se refiere a la posesión pacífica de los resguardos (“... para que nos represente en las diligencias que se deben practicar para el efecto de crear el título a que nos hemos referido"). 
punta de reja; por el occidente, con la hacienda denominada "El Campanero" de propiedad del Señor Enríquez Salas Pérez y otros más y también con la hacienda del Señor Manuel José Luna, quebrada Casanare por medio, luego y frente a un potrero atraviesa el lindero desde la quebrada Casanare para arriba siguiendo en un todo y lindero de la hacienda del expresado Señor Luna hasta llegar a la cimas desde donde se divisa la Ciudad de Pasto, de aquí linda con el Resguardo de la Parcialidad de Jamondino, cuchilla al medio, esta cuchilla hacia abajo hasta llegar a un árbol de manduro marcado con dos cruces, de allí para abajo a dar a otro manduro señalado con una cruz, por el Norte con el resguardo de Puerres y Canchala, zanja y bordo al medio; de aquí el camino de la Cuchilla que conduce al pueblo de Mocondino, sirviendo este camino de lindero entre las Parcialidades de Mocondino y Jamondino, hasta dar a un mojón divisorio de los Jamondinos con los herederos del Señor Braulio de la Rosa, de este mojón hacia abajo siguiendo, por el mismo camino deslindado ya el Resguardo de Mocondino con la hacienda de los Señores Rosas hasta llegar a una boca zanja, la que servía a poco trecho, de allí sigue una cuchilla zanjada en parte y en parte sin zanjar, la que va a descansar a propiedad de Ramón Jojoa deslindado en toda la extensión desierta con la finca denominada Chiriurco de Rómulo Chicaiza Nieto y José Rafael Agreda y Doctor Luis E. Gavilanes hasta topar con el Pueblo de Puerres y Cánchala, zanja a bordo al medio; de allí linda con el potrero llamado "Bomba" de los huérfanos, camino y zanja al medio, de allí con la finca de Burbanos, Florentino Paz, Padre Juan Bautista Rosero, heredero de José Moisés Matinés y Fidencio Luna, Germán Martínez, Julián Jojoa y de otros muchos más propietarios hasta llegar a la quebradas Tambillo y sigue ésta aguas arriba hasta el punto denominado Tambillo, de aquí cruza lindero con la parcialidad de la Laguna hasta dar a la Cima Casanare y filo del Tábano, en toda esta extensión hay camino en parte por medio y en parte zanja. ${ }^{\mathbf{1 6}}$

Estos testimonios fueron recibidos por el Fiscal del Circuito de Pasto y siguieron su curso ante el Juez $1^{\circ}$ del Distrito y el Personero Municipal. Así quedó consignado el 18 de Noviembre de 1937:

Según averiguaciones que hemos hecho con nuestros mayores sí han existido títulos de propiedad de dicho común en las notarías de este Circuito, pero que en virtud de un saqueo que ocurrió en dicha notarias en el año de 1840, tales títulos habían desaparecido. Posteriormente hemos hecho las averiguaciones del caso con el fin de averiguar el paradero de ellos, pero es lo cierto que hasta la presente ningún dato hemos podido obtener al respecto. Añadimos que no solo han existido títulos sobre el expresado común, sino que en ellos se ha hablado que este ha pertenecido a la parcialidad de Mocondino cuya propiedad acreditaban. Además las últimas correrías que hemos practicado con el fin de determinar la linderación, así como los planos que hemos hecho levantar, ha sido teniendo en cuenta los puntos de demarcación que los mismos antiguos nos han indicado como existentes en los títulos sobre la porción de terreno

16. Archivo General de la Nación, Sección República, Fondo Ministerio del Interior, Asuntos Indígenas, Caja 265, Carpeta 2523, año 1948, folio 60v1 y 66v. 
cobijada por el común de los terrenos de la Parcialidad a que nos venimos refiriendo. Esto es cuanto podemos informar en virtud del juramento que tenemos prestado. En este estado el señor Personero preguntó a los miembros del Cabildo que en qué forma habían hecho las averiguaciones de la no existencia de estos títulos; a lo cual contestaron que personalmente los informantes en compañía del Sr. Casabón Ch., hicieron las averiguaciones del caso, dejando además comisionado al Sr. Casabón para que prosiguiera las averiguaciones. En constancia firman con el Sr. Juez, Personero y Secretario que autorizo. Rafael Alcides Guerrero, O. Díaz del Castillo. Alcalde mayor Juan Bautista Jojoa, el Alcalde segundo Clodomiro Pinto, el Regidor mayor Modesto Jojoa, el Alguacil Luis Emigdio Naspirán y los Fiscales y Fiscalitos Eusebio Jojoa ${ }^{\mathbf{1 7}}$.

Y el Ministerio Público, representado en la Fiscalía del Tribunal Superior de Pasto, con fecha del 22 de Noviembre de 1927, dictaminó que:

En cumplimiento de los dispuesto en los Artículos 12 de la Ley 89 de 1890 y 40 y 41 del Decreto 74 de 1898, que la reglamenta, este Despacho estima suficiente la prueba creada a petición del Cabildo de Indígenas de Mocondino, que presentó el memorial fechado el ocho del presente, y dispone que se protocolicen tales diligencias en la Notaría $2^{a}$ de este Circuito, para que ella sirva a dichos cabildantes, como título de propiedad. A la escritura de protocolización concurrirá el Cabildo de Indígenas mencionado y el suscrito Fiscal, por mandato de los Artículos ya citados. Remítase, en consecuencia tales diligencias al señor Notario No. $2^{\circ}$ de este Circuito, con nota de atención ${ }^{\mathbf{1 8}}$.

Así se hizo, configurándose las diligencias que constan de 23 hojas útiles en papel común, y que, en lo pertinente, expresan singularmente:

... en consecuencia desde ahora y para siempre inserto las indicadas diligencias en el Libro de Protocolo Número Segundo del corriente año, en el lugar y bajo el No. que le corresponde, para que forme parte integrante de él, para que en todo tiempo puedan los interesados obtener las copias que les convenga; $y$, en fin, para que el acto surta todos los efectos civiles señalados por la Ley. Se les advirtió el deber de hacer registrar la copia de este instrumento en la oficina respectiva, dentro del término legal ${ }^{\mathbf{1 9}}$.

17. Autorización del Fiscal para que se protocolicen tales diligencias en la Notaría $2^{\text {a }}$ de este Circuito e Informe jurado de los cabildantes Alcalde mayor Juan Bautista Jojoa, el Alcalde segundo Clodomiro Pinto, el Regidor mayor Modesto Jojoa, el Alguacil Luis Emigdio Naspirán y los Fiscales y Fiscalitos Eusebio Jojoa, ante el señor Personero Municipal, en Pasto a los 18 días de noviembre de 1927, sobre la no existencia actual de los títulos de propiedad del Común de Mocondino Perteneciente a esta parcialidad. Juzgado $1^{\circ}$ Municipal, Archivo Histórico de Pasto, Fondo Notarías, año, 1927, folio 22 .

18. Diligencias dirigidas al señor Fiscal del Tribunal Superior, por el Cabildo de la parcialidad de Mocondino, para efecto de la creación de un título y de la recepción de una prueba. Firma como Fiscal: Carlos Benavides Guerrero. Archivo Histórico de Pasto, Fondo Notarías, Año de 1927, folio 217.

19. Ibíd., folio 233. 
Consta, además, que esta escritura les fue leída a los otorgantes, en presencia de los testigos instrumentales nombrados, quienes la aprobaron y aceptaron en todas sus partes. En constancia firmaron todos con los testigos instrumentales, ante el Fiscal: Carlos Benavides Guerrero, que dio fe. Firmaron a continuación del Fiscal los cabildantes representados en don Juan Bautista Jojoa, don Clodomiro Pinto, don Modesto Jojoa, don Emigdio Naspirán, don Eusebio Jojoa y como testigos don Enrique Narváez M. y don Gabriel Patricio Jojoa. Igualmente el Notario Segundo: Rafael Uribe.

\section{LAS CONTROVERSIAS AUTONÓMICAS}

Aunque los indígenas agrupados hoy como quillacingas, a diferencia de los Pastos, no libraron mayores movilizaciones frente a la Ley 19 de 1827 y del Decreto 2459 de 1939, en defensa de los Resguardos y de la Ley 89, sin embargo, como lo expresa el contenido central de las diligencias, en lo sucesivo, el acto de reconocimiento del Título surtió los efectos civiles señalados por la Ley en diversos campos de la vida de la Parcialidad, el Resguardo y Cabildo de Mocondino. No solo en lo pertinente a la cotidiana atención sobre la posesión y usufructo de los terrenos de resguardo, sino en temas de crucial trascendencia.

Sirvió, por ejemplo, para saldar diferencias y conflictos con la parcialidad vecina de Jamondino, en la región que disputaban llamada Mundo Loma y ríos Casanare, San José y Jurado y Cordillera del Diente, como consta en el Acta del 2 de febrero de 1937, firmada en la Alcaldía Municipal, en la cual los cabildos de Mocondino y Jamondino (con presencia del Alcalde municipal, su Secretario, el Ingeniero Inspector de Bosques nacionales y los cabildos de Botanilla, Males, Jongovito y Gualmatán), expresan "el deseo de una firme PAZ, conviniendo respetar la alinderación limítrofe que de común acuerdo y con intervención del ingeniero del Ministerio de Industria, ha quedado demarcada y amojonada por ambos pueblos"20.

También para legitimar y legalizar, mediante Acuerdo del Cabildo, el nuevo Cementerio Público de Mocondino, que aún persiste, "para atender ese servicio de utilidad pública e interés social”, a través de un proceso y juicio de segregación de un terreno de resguardo, propio. ${ }^{21}$ Obra tan necesaria, decía, "como el templo para orar y la escuela para instruirse". Templo y escuela que igualmente habían construido con la contribución del trabajo de la parcialidad, en terrenos de resguardo y bajo la autoridad del Cabildo.

Al someter el Acuerdo a la consideración del Alcalde Municipal para su aprobación, con las respectivas declaraciones de los testigos, el Cabildo de Mocondino sustantivaba en el derecho que le asiste sobre su propio resguardo:

20. Ver Carpeta en papel de Mocondino.

21. Acuerdo del 23 de febrero de 1945. Expedido en la casa del cabildo de Mocondino. Firmado por el Alcalde Mayor Anselmo Jojoa, el Alcalde $2^{\circ}$ José Rafael Muñoz, el Regidor Aurelio Naspirán, el fiscal Florentino Jojoa y los Fiscalitos Gonzalo Naspirán y Simón Jojoa. Declaran en forma extrajudicial sobre la veracidad de los argumentos del cabildo: José Delfín Jojoa y Luis Emigdio Naspirán. 
No es por demás llamar la atención del ilustrado criterio de Ud. sobre el Acuerdo, en terreno del resguardo, del cual sí puede disponer el cabildo, no sólo por tratarse del Cementerio que interesa totalmente a la población sino porque siendo la muerte un fenómeno natural, en toda población. Se necesita del templo para orar, de casa de escuela para instruirse y del campo santo para morada de los muertos. ${ }^{22}$

Y el Alcalde Municipal aceptando los argumentos sociales y legales del Cabildo, el 28 de febrero de 1945, le aprueba dicho Acuerdo:

En estas circunstancia y teniendo en cuenta que el Acuerdo en mención llena un cometido y una finalidad por demás dignas de encomio y por otro aspecto que con esta adjudicación en nada se contraría al espíritu de la Ley 89 de 1890 y decretos reglamentarios, antes sí se conforma y basa en las respectivas disposiciones, la Alcaldía, administrando justicia en nombre de la República de Colombia y por autoridad de la Ley, RESUELVE, aprobar en todas sus partes el Acuerdo que se ha hecho mérito.” Firma el Alcalde Bolívar Hinestroza. ${ }^{\mathbf{2 3}}$

En marzo 7 de 1945, a las 9 am, el honorable Cabildo de Mocondino da posesión del cementerio a su pueblo. Firman los miembros del Cabildo y todos los asistentes. ${ }^{\mathbf{2 4}}$

Alternativamente a la continuidad de la vida indígena en sus resguardos, los intereses ideológicos y políticos feudal-capitalistas persisten en reducir a los indígenas a la vida civilizada, liquidar los Resguardos Indígenas para que estas tierras entren a la economía como propiedad privada. Cerón y Ramos afirman al respecto.

La integración de la región de Pasto al mercado modifica rotundamente la tenencia de la tierra; de modo que los resguardos indígenas en cierto modo habían descansado de las presiones de terratenientes, ahora son objeto de voracidad de la clase dominante que amparada por el Estado termina por disolverlos. En 1940 hay 88 resguardos en Nariño ocupando cerca de 70.000 hectáreas de tierras fértiles y bien ubicadas. Los más codiciados corresponden al Valle de Atriz debido a la cercanía a Pasto y su excelente vocación agropecuaria. Se aplica el decreto ley 1421 recurriendo al fácil recurso de exigir títulos. Como el requisito es imposible de cumplir, se declaran estas tierras baldías y a los indígenas: colonos, a quienes se les reconoce únicamente el área cultivada (Cerón, 2012: 132).

22. Ver Carpeta en papel de Mocondino. Archivo Histórico de Pasto, Fondo Cabildo, Caja 430, Año (sf), Tomo (sn), folio 199.

23. Ver Carpeta en papel de Mocondino. Archivo Histórico de Pasto, Fondo Cabildo, Caja 430, Año (sf), Tomo (sn), folio 196.

24. El lote se denomina El Arrayán, parte integrante del terreno denominado La Casa, que fue adjudicado por el cabildo al esposo de Clara Naspirán, José Delgado Jojoa, por Acuerdo del 8 de octubre de 1908, quedando a su muerte como herederos Andrés y Elías Delgado Naspirán. Junto a "La Casa” le fue adjudicado los terrenos El Llano" y "El Potrero" (ver foja 18 en adelante, de la querella interpuesta por Clara Naspirán. En su primer matrimonio fue casado con Elvira Jojoa con quien tuvo como hijo a Andrés Delgado. A la muerte de Elvira contrajo segundo matrimonio con Clara Naspirán, con quien tuvo como hijos a Elías, Florentino, Gonzalo, Angel María, Filomena y Julia Delgado Naspirán). 
En consecuencia, persisten en aplicar la Ley 19 de 1927 parcelando los resguardos a través de comisiones repartidoras, ahora viabilizando tal acción mediante el Decreto 2454 de 1939, e induciendo estratégicamente a los indígenas a aceptar la repartición haciendo uso de los conflictos internos, los desmanes de los cabildos, la mestización y el espejismo del progreso.

En oficio de agosto de 1939, al Ministro de la Economía Nacional, comuneros de la Parcialidad de Mocondino consideran necesaria la repartición del resguardo y aseveran que son los cabildantes los que se oponen, "pues los cabildos con sus familiares que se han apoderado de las mejores y más extensa zonas no quieren la división" ${ }^{25}$. Además, "temen perder el honor, poder y las anheladas consecuencias del Gobierno Económico que les da el Artículo 4 de la Ley 89 de 1890”. Para lo cual, tienen sofismados a los condueños con amenazas de que el Gobierno les dará una o dos cuadras y que el resto lo tomará el mismo gobierno; que pagarán el impuesto de uno por ciento y otros artificios que deshonran al Gobierno". Además, "el continuismo de los cabildos es perjudicial a la economía nacional, a las industrias y al progreso de la Patria"26.

Consideran, además, que la repartición les dará la oportunidad de disponer libremente de lo propio, liberarse de la condición de parias, menores de edad, inhábiles, bajo el tutelaje de las roscas a lo que los tiene sometidos el gobierno.

... siendo los primeros ocupantes del suelo que por lo menos en número de cincuenta mil indígenas surtimos como campesinos los mercados de víveres nos tenga el gobierno como parias y bajo el tutelaje de las roscas, como menores de edad e inhábiles para disponer libremente de lo propio, no podemos continuar por más tiempo en tal situación, porque nos creemos fuertes, vigorosos y preparados para atender a nuestras necesidades ${ }^{27}$.

Creían que con la repartición del resguardo podían librarse de la opresión y de la dominación,

25. Casos que pueden corroborar tal comportamiento: José Antonio Erazo, de Buesaquillo, solicita al Inspector de Policía Declaración Jurada, si los terrenos "Casa Japachoy “, El Pueblo” o "Jural”, la Loma, "El Anima", El Oso" o "Palo Quemado" de 3, 2, 6, 8 y 1 1 \$2 hectárea, fueron adjudicadas por el cabildo de la extinguida parcialidad de Indígenas de Buesaquillo, a su finado suegro Manuel Piandoy y su Esposa Carmela Matabanchoy (Archivo Histórico de Pasto, Fondo Cabildo, Caja 430, Año 1951-1952, Tomo 1, f. 84).

26. En 1948 en La Laguna, Clímaco, Néstor, Juan y Marcial Jojoa solicitan adjudicación de los lotes de terreno denominados "La Esperanza" o "Cabrera", "El Hueco" o "Quebrada”,"Ubsapamba", "Minas", "Huilquipamba” o "Yacuro", "La Planada, "La Puerta” y "El Retiro", en condición de colonos y cultivadores y como poseedores exclusivos (Archivo Municipal de Pasto, Fondo Cabildo, Caja 415, Año 1948, Tomo 19, folios 71-86.

Archivo General de la Nación, Sección República, Fondo Ministerio del Interior, Asuntos Indígenas, Caja 265, Carpeta 2523, año 1939, folio 50.

Dice el Artículo $4^{\circ}$ : En todo lo relativo Gobierno económico de las parcialidades tienen los pequeños Cabildos todas las facultades que les hayan transmitido sus usos y estatutos particulares, con tal que no se opongan a lo que previenen las leyes, ni violen las garantías de que disfrutan los miembros de la parcialidad en su calidad de ciudadanos.

27. Ibíd. 
En 130 años de vida republicana hemos vivido bajo el despotismo de los gobiernos de la raza blanca y de las tramoyas de la política para el manejo de nuestros terrenos que desde la conquista fuimos despojados de las zonas empastadas y arrojados a los bosques huyendo de la persecución ${ }^{\mathbf{2 8}}$.

Rogamos a su señoría hacer todo lo que esté en sus atribuciones para que se lleve a efecto la división de los resguardos, votando en el presupuesto de Rentas y Gastos la partida correspondiente, cuyo número de habitantes en Mocondino es el de 630. Este es el mejor servicio que puede hacer el actual gobierno al campesinato indígena ${ }^{\mathbf{2 9}}$.

El 5 de septiembre de 1939, en oficio al Ministro de Industrias y Economía Nacional, José Alfonso Jojoa, le refiere que "durante 120 años de vida republicana el Gobierno de los Cabildos ha sido embarazoso para el progreso del país, y que, por consiguiente, "no podemos continuar por más tiempo bajo el régimen de la Ley 89 de 1890, perjudicial para nuestros intereses y también para las industrias pecuarias y agrícolas”.

Sin embargo, alternativamente, el 7 de septiembre de 1939 en oficio al mismo Ministro de Industrias y Economía Nacional, el Alcalde Mayor Eusebio Jojoa, el Alcalde Segundo Macario Pachajoy y el Regidor José Adán Jojoa, le clarifican que "los títulos del Resguardo reposan en el Ministerio de Trabajo y Obras Públicas; que "de ninguna manera se conviene en la venta porque al otro día de la división nos quedaríamos en la calle, porque todo se lo habrían comprado los blancos”; que el problema central es la escases de tierra, pues "hoy por hoy el indio ni es comerciante, ni médico, ni nada de las profesiones liberales, sin la tierra es como ha tenido que esclavizarse en las haciendas"; que se agravaría, porque "sin duda el partidor y demás gastos, para pagarse de sus honorarios harían lote de gastos, lo más gordo del resguardo"; que, por consiguiente, "pedimos que mejor se nos auxilie con herramientas y semillas, lo demás lo resolverá el tiempo”30.

Empero, mediante Oficio del 13 de mayo de 1943, el Cabildo de Mocondino, representado en el Alcalde Mayor José María Naspirán, el Alcalde Segundo Jorge Enrique Jojoa, el Regidor Miguel Angel Jojoa, el Alguacil Pedro Pablo Jojoa y el Fiscal Gratiniano Jojoa, expresan al Ministro de Economía Nacional,

Que habiendo sido informados por el doctor Emiliano Rey Zúñiga de las medidas que el gobierno piensa llevar la adjudicación en propiedad a los habitantes de la parcialidad de los resguardos por lo tanto, tenemos el placer a manifestar a su señoría expresamente que estamos de acuerdo con dichas medidas y dispuestos a presentar todo nuestro apoyo para que se realice pronto la adjudicación en propiedad que solicitamos por medio del presente memorial ${ }^{31}$.

28. Ibíd.

29. Ibíd.

30. Archivo General de la Nación, Sección República, Fondo Ministerio del Interior, Asuntos Indígenas, Caja 265, Carpeta 2523, año 1939, folio 38.

31. Ibíd., año 1943, folio 36. 
En julio 7 de 1947, a petición de Jorga A. Díaz R., representante de quienes estaban de acuerdo en la extinción del resguardo, solicitan al Notario No. $1^{\circ}$ del Distrito sobre la existencia o no del Título colonial en los Libros Protocolos. El notario Alfredo Santander certifica que "no se encuentra el título originario de la Corona Española sobre trasmisión de dominio de los terrenos del Resguardo de Mocondino, de este Municipio, y a favor de la parcialidad nombrada"32.

Y en agosto 8 de 1947, mediante oficio al Ministro de Economía Nacional. Departamento de tierras. Sección de Baldíos. El Alcalde $2^{\circ}$ Gonzalo Jojoa, el Fiscal $1^{\circ}$ Juan de Dios Jojoa y el Fiscal $2^{\circ}$ Esteban Emiliano Jojoa, al rendir informe en las diligencias sobre la extinción del resguardo, expresan que "El Resguardo de Mocondino no tiene problema de límites con los terrenos vecinos, ni existen litigios en cuanto a dominio de tales terrenos. Dentro del resguardo no hay individuos extraños. No existen títulos originarios de la Corona española sobre la propiedad de los terrenos del Resguardo, ni se sabe si han existido o no"33.

En agosto 18 de 1947, considerando que el resguardo de Mocondino se encuentra en las mismas condiciones de las parcialidades de Pandiaco, Catambuco, Tangua, Pejendino y Santa Bárbara, las cuales fueron declarados extinguidos, por carecer del título originario de la Corona española, no reuniendo, en consecuencia la condición requerida para tener vida jurídica, declarando esos terrenos parte del patrimonio del Estado y que los indígenas pueden obtener la adjudicación en propiedad de sus respectivas parcelas; “... por lo que acudimos a su señoría en solicitud de la declaratoria de su inexistencia"34.

Consideran ventajoso que se obtenga un título de propiedad emanado del Estado, porque "es más estable que un título expedido por un cabildo".

La inestabilidad e inseguridad de un acuerdo expedido por una cabildo son notorias, puesto que cada vez que hay cambio de Cabildo ocurren segregaciones que causan perjuicio al adjudicatario, ya por lo reducido de los terrenos que usufructúan, ya también por las mejoras que se han puesto en el terreno, de las que se priva a la persona a quienes le hace la segregación sin la correspondiente indemnización.

Por otra parte los terrenos se hallan divididos y subdivididos, de suerte que los indígenas a lo sumo alcanzan a tener una hectárea, con la que atienden a las necesidades propias y de sus familias, y no es pues que de una insignificante parcela de la capacidad anotada los cabildos hagan nuevas segregaciones. El individuo perjudicado naturalmente tiene que ocurrir a un pleito en el que erogan sumas que en muchos casos sobrepasan al valor del terreno. Como en cada año hay cambio de cabildo y no faltan motivos para dichas segregaciones, resulta que de este modo los pleitos son interminables ${ }^{\mathbf{3 5}}$.

32. Archivo Histórico de Pasto. Fondo Notarías, Año de, folio 25r. Es claro que los documentos fueron arrancados del libro correspondiente.

33. Archivo General de la Nación, Sección República, Fondo Ministerio del Interior, Asuntos Indígenas, Caja 265, Carpeta 2523, año 1947, folio 16r.

34. Ibíd., folios 29-30.

35. Ibíd. 
Además, expresaron que "un título de propiedad emanado del Estado vincula más indígenas a la tierra. Que es la fuente de su vida. En tanto que en la propiedad común, si es que existiera el título de propiedad, el indígena no es sino un mero usufructo sujeto a la incertidumbre de la instabilidad de su título". Que "se le obliga también a pagar tributos so pena de perder el terreno". Que "sufre vejámenes aún en lo moral, porque los Cabildos tienen también derecho de fiscalizar los actos morales o inmorales de los indígenas, con un poder omnímodo, esto es como verdaderos caciques".

Sobre la Ley 89 de 1890, consideraron que para ellos había perdido vigencia puesto que ya no eran de incipiente civilización o menores de edad:

La Ley 89 de 1890 fue dictada para agrupaciones de incipiente civilización, para individuos a quienes se creía incapaz de gobernarse a sí mismos, como inhábiles para administrar y disponer de sus bienes. Ahora el grado de cultura y civilización de los indígenas no es el mismo que el de antaño; la civilización ha cundido a las comarcas. Ya nos consideramos capaces de administrar nuestros bienes, no como menores de edad, sino como verdaderos hombres, como verdaderos ciudadanos. No es justo, pues, que a nosotros no se nos puedan aplicar las leyes generales de la República que se aplica a todos los que son ciudadanos.

Finalmente, concluyeron el informe con los linderos del resguardo en extinción, así:

Por el Oriente, con terrenos de finca "Campanero, cordillera ya citada, en donde nace un rio, aguas abajo hasta los terrenos del Pbro. Dr. Juan Bautista Rosero, Quebrada por medio; de aquí aguas arriba lindando con terrenos del mismo Pbro. Dr. Juan Bautista Rosero, la familia Luna, herederos de Sixto Jojoa y Miguel Jojoa, hasta un callejón que transitan los habitantes de Mocondino, sigue camino abajo lindando terrenos de los Lunas, Manuel Castro, German Martínez, Julián Jojoa zanja con agua por medio; de aquí aguas abajo lindando con terreno de Julio Jiménez hasta un camino antiguo de transitar los habitantes de la sección de "Dolores", sigue por el mismo camino lindando terrenos de Florentino Paz, Salomón Burbano y herederos de José Burbano hasta el camino de transitar los indígenas de las parcialidades de Puerres y Canchala. Por el Occidente, con la finca "La Bomba" de propiedad del asilo de San José sigue con terrenos de las parcialidades de Puerres y Canchala, camino y zanja por medio sigue lindando con terrenos de los herederos del Dr. Isaías Inestrosa, de allí que lindando con terrenos de las Parcialidades de Jamondino, cuchilla camino y mojones por medio hasta dar a la finca Campanero, punto partida ${ }^{36}$.

36. Archivo General de la Nación, Sección República, Fondo Ministerio del Interior, Sección de Asuntos Indígenas, folios 29-30v. 
Firmaron, entre otros ilegibles en la fotocopia: José Delfín Jojoa, José Rafael Muñoz, José Adán Jojoa, Víctor Rosales, Modesto Jojoa, Lucas Abrahán Jojoa.

Se expresó en el proyecto que, desde mediados de la década de 1990, algunas de estas antiguas parcialidades iniciaron el proceso de reconstitución de los resguardos y cabildos indígenas que habían existido allí hasta 1950. Hoy, en cinco corregimientos del municipio de Pasto existen cabildos organizados y una gran proporción de sus habitantes se auto reconocen como indígenas quillasingas. Este proceso de reivindicación étnica inició a mediados de la década de 1990 por pobladores de El Encano, posteriormente por pobladores de La Laguna y Cabrera, lo mismo sucedió en Jenoy en el año 2008 y procesos similares tienen lugar en Obonuco y Mocondino.

Ante este hecho, la percepción de la sociedad local, de los intelectuales y, sobre todo, de los gobiernos local y nacional es ambigua. Por un lado, se reconoce la validez histórica y social de estos procesos y algunas de estas comunidades hasta cuentan con el reconocimiento oficial por parte del Estado, concretamente El Encano-Refugio del Sol, el Resguardo de La Laguna-Pejendino y Jenoy, pero, igualmente, se cuestiona como contrarios al progreso, de tal manera que las autoridades locales han puesto en entredicho su legitimidad y legalidad.

Hay visiones y actitudes poco profundas y en ocasiones malintencionadas que desubican la mirada de aspectos histórico-sociales y culturales que enmarcan los fenómenos de reivindicación étnica, y, sobre todo, no toman en cuenta la perspectiva histórica de la vida de estas poblaciones en relación con los modelos y políticas económicas, sociales y estatales, que, obviamente, no inician en 1991. 


\section{REFERENCIAS}

1. CERÓN, Benhur y RAMOS, Marco Tulio (1997). Pasto:espacio, economía y cultura. Banco de la República. www.banrepcultural./org/blaavirtual/geografia/Pasto. Parte2/Cap1-1.htm.

2. FALS BORDA, Orlando (1959). "El vínculo con la tierra y su evolución en el Departamento de Nariño". En Revista de la Academia de Ciencias Exactas, Físicas y Naturales. 10 (12): 9-14. Bogotá.

3. MAMIÁN, Dumer (2000). “Rastros y rostros de un camino para andar". En Revista Mopa-Mopa. No. 14. Pasto: Instituto Andino de Artes Populares, Universidad de Nariño, .

\section{ARCHIVOS CONSULTADOS}

Archivo General de la Nación - Bogotá D.C.

Archivo Histórico de Pasto - Pasto.

Ley 89 del 25 de diciembre de 1890.

Ley 19 de 1927. Decreto 2459 de 1939.

Decreto-Ley 1421 de 1943. 